\title{
Do Holistic Visions of Nature Enhance Ethical Relations between Man and Environment?
}

\begin{abstract}
The visions of the natural world built by man also shape our relationship with respect to the environment. In the present paper I would like to demonstrate how these holistic ideas, like the Gaia Hypothesis, affect ethical relations with nature. Do they enhance the need to treat nature in accordance with ethics, are they ethically neutral, or do they convince us that man has no ethical obligations to the environment whatsoever? "The Gaia Hypothesis” can be ambivalent in this respect, but in the end it leaves no doubt that, even though other species do what man does, Gaia (biosphere) has a limited tolerance for negative effects of human activity. And although we are not able to annihilate the life on the Earth, we are certainly capable of destroying the conditions necessary for our subsistence.
\end{abstract}

\section{Keywords:}

ethics, environment/nature, the Gaia Hypothesis, evolution, alchemy, pollution, threat

1 Institute of Philosophy, Faculty of Social Sciences, University of Wrocław, Poland, zbigpietrzak@wp.pl. 


\section{INTRODUCTION}

The relationship of man with the surrounding nature has never been neutral. Nature has conditioned his survival but it has also been the source of lethal threat; it has provided an aesthetic inspiration, but it has also filled man with terror. Nature has always been terrifying on account of its enormity and its indifference towards man's fate and mortality, as it has invariably been reborn in an ongoing cycle of birth and death. Surely, among these various relations between people and nature, a certain relationship has grown to be essential in the shaping of man as an intelligent species. We might call it an ethical relationship. It is not possible to establish when such an ethical relationship was established or what lay at its root. We may only conjecture that it is some immanent property of mankind which constitutes our mind, sensitivity and emotionality, just like aesthetical or cognitive thinking.

An issue that I would like to broach in the present deliberations is related to ethical relations (and their consequences) that we build in respect to natural environment in the context of preferred visions of nature. Do these ideas enhance our "ethics" against the surrounding nature, or do they enfeeble it? Do they exempt man from the responsibility, in his view at least, for nature? Or perhaps they are absolutely neutral, i.e. they do not generate contradictions in our relations with the surroundings regardless of our ethical values. They do not demand that we act in a particular way towards it or make any decisions.

However, before we investigate these ethical relations, how to understand them and what they would consist in, let us briefly analyse the selected holistic visions of nature.

\section{ALCHEMICAL IDEA OF SPIRITUAL AND MATERIAL UNITY OF THE WORLD}

Although the vision of the world formed by alchemy departs from, or is even inconsistent with, the attempts at a holistic depiction of nature, I think that its ideas, and principally the manner of comprehending the surrounding reality, which is universal for our species ${ }^{2}$, should comprise a reference point for the conceptions of nature that are currently acceptable.

2 I take the liberty to use this biological or naturalist notion as this type of thinking about nature is typical for all cultures. It is universal in the sense that its manifestations can be found in the entire history of mankind. It may have evolved in the archaic times, before the ultimate dispersal of our species. 
What constitutes the idea of an alchemical perception of the world is the conviction of its material unity as well as of the unity of matter and spirit. This unity and uniformity is therefore multifaceted and 'multidimensional'. The world, although it presents itself as versatile, sometimes chaotic and discontinuous ${ }^{3}$ becomes an entity, a quasi-organism which has only one history and one goal (these convictions are expressed in the myths of the unity of the Cosmos). Believing that the reality which surrounds us has a shared history, and that we are, at least in a global dimension, an element of some universe, forces upon every being a particular approach to its own surroundings. It is best manifested in myths and magical and alchemical practices. Regardless of whether we refer to archaic times or to the Middle Ages or the Renaissance, the world in an alchemical perspective presents itself as an entity that develops and pursues a certain goal. In his book Blacksmiths and Alchemists, Mircea Eliade describes the way this unity and the 'evolutionary character' were viewed and expressed. The Earth and Cosmos constituted an arena for the pervasive spiritual powers which changed their status causing all substance to become an element of an animated universe. Thus, "minerals belonged to the sacredness of Mother Earth. We can encounter very early beliefs that ores 'mature' in the Earth's belly like embryos” (Eliade, 2007, p. 6). The Earth is then perceived and treated as a live organism which naturally imposes a certain type of relationship between it and miners or steelworkers for example. Therefore, "metallurgical industry is like obstetrics. Miner and steelworker interfere with the course of subterranean maturing: they enhance the development of ores” (Eliade, 2007, p. 6) etc. When man interferes with natural processes he becomes responsible for them, not only in material and exploratory terms but also spiritually. Therefore, "the smelter, the blacksmith and the alchemist have one thing in common: they are involved in a unique magical-religious experience related to an attitude towards matter (...) all three of them work with matter which is sacred and live alike, and their works continue its changes, its refinement, its “transmutation'” (Eliade, 2007, p. 7). In practice this meant that perceiving the Earth as a live organism and the resources as its foetus, they were treated as animated substance. Just like in the case of forest, cropland, water resources and fossil explorations, it should be left for recovery. The Earth and its fruits needed time to rebuild its resources and for that goal the exploitation of resources was discontinued.

3 'Discontinued', 'mutational' in the sense presented by Leszek Kołakowski; cf (Kołakowski, 1994). 
The vision of a spiritual and material unity of the world had a similar impact on shaping the alchemy of the Renaissance. ${ }^{4}$ A particular emphasis was laid upon the idea of a common origin of all the elements of the world calling it the source/ root, also understood as the mysterium, prima materia elementorum, etc. On the other hand, he treated the Cosmos as an entity that was developing from an undifferentiated form which: "like a tree - branches out, disseminates from inanimate beings, from the most basic and primitive elements, to increasingly pure, perfect, organised, animated and conscious entities and elements” (Koyre, 1995, p. 99). In this gradual transition (transmutation) from simple to increasingly complex entities, a vision of a perfecting world shines through. But on account of the fact that the world of substance is integrated with the spiritual world (each entity, each component of matter is 'equipped' in the principle of life - archeus) then the perfection was effected also in the non-material dimension, preserving the same transcendent nature. 'Does the process of the spiritual rebirth - Koyre asks - is something else than the alchemical process? Is not a primitive body transformed into a spiritual body through the medium of the magisterium of spirit and isn't our soul going through the same stages (...) as the matter and the world?” (Koyre, 1995, p. 102). This bond of both dimensions - the transcendental and the material, causes the alchemy to be soaked with the ethical thought. It was in a sense a code which made moral demands on both the masters and the disciples. An arcane art, as the alchemy was regarded, required relevant qualifications, not only substantive but also spiritual and moral. Therefore, it is full of initiation rituals and magical practices. The alchemist, when preparing to laboratory work, went through a series of strictly defined stages which aimed at absolving him from sins and preparing to commune with a mystery of the prayer, hence the fasting.

However, the blacksmith and the alchemist, like a naturalist of today had a desire to claim 'power' over the world of substance and time. However, a different understanding of nature by the former and contemporary scientists as a consequence led to significantly different practices.

4 I overlook the ideas of Aristotle such as entelechy and hylozoism, which may be considered as foundations of medieval alchemy and later times. 


\section{SELECTED CONTEMPORARY CONCEPTIONS OF NATURE ${ }^{5}$}

Archaic and subsequently modern alchemy shaped the ability to think about nature as a whole. The Cosmos, the Earth and all the living organisms and inorganic substance helped to create, in compliance with these conceptions, a system of related entities, from their creation to the goal they were supposed to achieve. Although man always viewed himself as an entity that was more or less independent of the remaining 'beings' that fill the Cosmos, his history has consistently interwoven with nature and has been dependent on it. It appears that it was not until the advent of the modern era that shook the conviction of the unity of the world. However, this 'atomisation' of nature took an ambivalent course. On one hand, owing to astronomical observations and the idea of geometrisation of space, Galileo and Descartes made the Cosmos 'uniform', thereby abolishing the Aristotelian dualism of the sublunary and celestial world. On the other hand, Descartes dug a precipice between man and the other living organisms treating the latter like machines. What is more, in order to add to the differentiation of substance yet another demarcation line - the nature came to be perceived as animate or inanimate thus putting an end to the hylozoic vision of the alchemists. Nature became dual again, in terms of ontology and cognition.

In the $18^{\text {th }}$ and $19^{\text {th }}$ centuries natural knowledge partially neutralised this distinction acknowledging animals to be more than machines devoid of sensations. However, man preserved the status of the exceptional 'animal', intelligent and possessing a soul. On the other hand, the Cosmos and the Earth, owing to Isaac Newton's work, ceased to be the divine domain and the arena of unknown connections, and thanks to gravity, mutually related objects. One might claim that the more earth's substance and earthly phenomena were differentiated, the more unified the entities and laws in cosmic scale were unified.

The announcement of the theory of evolution in 1859 caused (yet not in the minds of its opponents) the position of man to have radically changed. Man became one of the links in the chain of living organisms sharing a history and existence with them. Despite being distinctive in terms of intellect and spirituality, he remained

5 When considering holistic visions one might mention several other conceptions, less spectacular and constructing the unity of entities on a smaller scale, yet also influential and controversial. I mean the ideas of 'sociobiology' suggested by Edward O. Wilson, the idea of 'phenotype' and the 'extended phenotype' by Richard Dawkins, and the most philosophical idea of the 'chain of being' by Arthur O. Lovejoy. In my opinion all these conceptions provoke ethical considerations and are conducive to the queries of ethical relations of man against nature. However, the scope of this paper does not allow broaching these issues. 
biologically identical to the surrounding animals and plants. Could man's ethical attitude towards nature be affected by this change of status? Could it be shaped anew, making people responsible for the future of nature ${ }^{6}$ ?

In mid-1900s ${ }^{7}$ a conception was suggested which later came to be known as the 'anthropic principle'. Whichever version of the principle we will refer to, either 'weak' or 'strong', it presents a coherent version of the Cosmos as a whole within all its structures and in its complexity. Let me briefly summarise the most principal assumptions of this well-known conception for the purposes of this paper. The Cosmos, in its full extent, was created as one material object ${ }^{8}$ and, although it may have its own 'local histories', as the Universe it has its universal time and history, to which the Earth and the people are subjected. The relationships and interrelations that this principle relates to refer back to the most fundamental laws of physics expressed in cosmological constants. The values of these constants are reportedly consistent, in a very narrow scope, with the requirements for life on the Earth as we know to have formed. What is important for these deliberations is the fact whether life, and the man, are a necessary result of the applicable laws, or have they appeared by way of alternative implementation of phenomena which might potentially lead to the existence of other organic realities. What links the anthropic principle with the theory of evolution is the evolutionary course of events - from the simplest material structures having the character of electromagnetic waves, to more complex structures on the atom, and subsequently macroscopic and cosmic level, until the emergence of mind. In other words, we may ask whether the world we know is necessary and independent of our actions or, at least in human terms, we are in control of its history, which puts us in the position of making ethical choices.

Yet another vision of nature, 'the Gaia Hypothesis' appeared in the 1970s, but it was inspired by antique myths. ${ }^{9}$ As far as the anthropic principle bound the history of the Cosmos into one string of events linked by universal laws, the Gaia

6 Cf. (Elżanowski, 2010).

7 In early 1900s Alfred Russel Wallace formulated a vision of nature which might be viewed as the predecessor of the anthropic principle. However, it was put under criticism by S. Jay-Gould; (Jay-Gould, 1991, pp. 310-311).

8 I overlook those conceptions which propagate the multitude of universes as too speculative for the fundamental context of the present paper. Deliberations of the multitude of worlds and their significance for the history of our visible Cosmos, or even for the fate of people, may of course be intriguing, yet from the perspective of man's ethical responsibility for the surrounding nature, not very revealing.

9 In Greek mythology Gaia is the goddess of the Earth. The contemporary ideas which might have been taken for the conception of the Earth-Gaia were formulated in the 20th century by F.E. Clements, A.G. Tansley. 
Hypothesis was an attempt at explaining the phenomenon of life - the phenomenon of its origin and its subsistence. ${ }^{10}$ The content of this conception overlaps the content of the anthropic principle in the part in which it emphasises the specific conditions required for the origination and survival of life. Like the anthropic principle, it points to a very narrow, and therefore unlikely, scope of cosmological constants which condition the evolution of the Cosmos leading to the origination of a conscious being, the Gaia Hypothesis focuses on unique processes that take place inside the Earth and in the Solar System, i.e. in immediate proximity with respect to cosmic scale. According to this conception, for the life on Earth to come into existence such conditions were required that were very unlikely or even impossible without interfering with the course of physical phenomena. In his book Gaia. A New Look at Life on Earth, James Lovelock quotes many statistics in favour of the uniqueness of the Earth's biosphere, atmosphere in particular, compared to the conditions on the other planets in our Solar System (Cf. Lovelock, 2003). ${ }^{11} \mathrm{He}$ emphasises the exceptionality of its current conditions which are imperative for life to come to existence, in relation to those which should function in 'normal' conditions (Lovelock, 2003, p. 54). Without delving into details of the author's argumentation one needs only to realise that the life on the Earth is, according to his arguments, in contradiction with the principle of entropy. ${ }^{12}$ The conclusions are as follows: everything points to the fact that life on the Earth must have originated because the required conditions appeared, contrary to the 'logics' of nature.

This time we can also ask, in the context of the vision of nature in which the Earth is presented as a 'caring Mother', if the question of our ethical relations with nature, which directly conditions our existence, is justifiable. Now then, does the idea of nature self-regulating towards the formation and sustenance of life make

10 In 2009 Peter Ward published a book under a provocative title The Medea Hypothesis. Is Life on Earth Ultimately Self-Destructive? This book gives an insight into how much the Gaia idea is subjective and relies on convictions that are beyond nature. The same data and the same methodologies lead to completely different conclusions. Ward suggests that the Gaia idea is a more of a philosophical vision rather than a scientific hypothesis. On the other hand one should note that the Medea conception is an ironic reply to the serious Gaia idea.

11 This book was written at the turn of the 1960s (published in 1979) when not only other earth-like planets had not been discovered but other planetary systems at all. The first planetary system (around a pulsar) was discovered by Prof. Aleksander Wolszczan. A hypothesis in respect to this event was proclaimed in 1992.

12 Modern cosmologies assume local disorders, e.g. in the disintegration of matter. Galaxies are such a 'disorder' - density of matter within them is far from the average density of matter in the surrounding space. They are in fact empty. It does not mean that there is perfect vacuum within them. The Cosmos is filled with gravitational and electromagnetic interactions, etc. 
us, as we are increasingly more acquainted with these conditions, be increasingly active in taking ethical actions towards it or, conversely, can we ignore them and favour the well-being of man? But can the well-being of man be implemented in separation from thinking about the environment and its 'well-being'? And, above all, what should this 'ethical thinking' and the 'well-being' of nature consist in?

The cognitive status of both conceptions is a separate issue. The question whether they are theories, hypotheses, theorems is not essential for the present deliberations. However, for their role in science this question may be key in the discussion about the nature of knowledge. Although in one case we use the term 'principle' and in the other 'hypothesis', shouldn't they be understood just like we understand the notion of a law in Newton's physics ('laws of motion') or hypotheses in natural sciences ('Lack's hypothesis', 'Fisher's hypothesis', Broglie's hypothesis). Neither are they theories in the understanding of the 'gravity theory' or the 'evolution theory'. Therefore, I have applied the term conception, idea or vision of nature, as none of these expressions shape their status in a particular way, or ascribe them to a particular discipline. All the more so, since both ideas, being the most general and encompassing many disciplines, seem to be immune to falsification. However, in relation to particular, detailed data, they might be subjected to it. Notwithstanding the objections, the question formulated in the title remains valid. ${ }^{13}$

\section{ETHICS IN GENERAL - ETHICS AND MORALITY}

As the present deliberations are not dedicated to the theory of morality, ethics and their history, I will only restrict myself to a few basic opinions that will allow a detailing of the problem of the idea of ethics in relation to nature.

Priority can be given to the issue of the sources of morality and ethical thinking in relation to environment (but also sources of morality in general). ${ }^{14}$ Ever

13 Lovelock himself remains ambiguous in this issue. On one hand he believes that the Gaia hypothesis in its original, most philosophical or even mystical understanding is, according to contemporary knowledge, false. However, a new understanding of this idea provides grounds to treat it as a thesis which may be called the 'theory of Gaia' as the underlying is the Daisyworld mathematical model and it can be tested and falsified; cf. (Lovelock, 2003, pp. 161-162). In this context see the remarks of January Weiner in his ‘Afterword' (Lovelock, 2003, p. 169).

14 The relationship between ethics and morality can be shortly defined by treating the former as the justification for morality or a rational analysis of morality. Thus ethics may be understood as a theoretical contemplation of the phenomenon of morality rooted in evolution; cf. (Elżanowski, 2010, pp. 46-48). 
since the emergence of the theory of evolution, particularly since the publication of the Origins of Man, naturalist ideas have found inspirations and arguments in their favour, just like Descartes' and then Kant's works were a source of transcendent ideas. In other words, regardless of whether moral or ethical questions had their transcendent, apriori, evolutional or naturalist sources they generated new arguments for discussion. A vision of an organic world evolving beyond the biological, provoked questions that went beyond the non-material aspect of nature. An evolutional interpretation of natural phenomena could be extrapolated to the world of values, and at the same time, by analogy one could look for their sources in biological processes by ascribing them a historic and changeable character. What is more, the evolutional origin of morality enhanced the evolutionary past of man. Here is how Andrzej Elżanowski puts it: "Darwin proposed a hypothesis on the evolutional origin of morality from 'social instincts'. There is a twofold interpretation of this hypothesis. It is above all a purely scientific hypothesis which is essential to prove the evolutionary origin of man (...) Secondly, this hypothesis, just as any theory of the evolution of morality, has major ethical implications" (Elżanowski, 2010, p. 15). Even a preliminary analysis of works dedicated to moral and ethical consequences of Darwin's theory highlights the importance and intellectual prolificacy of this issue. The article by Prof. Elżanowski, mentioned earlier, follows the course of the discussion, how it was shaped, and what problems related to the origin of morality and Darwin's theory were emphasised. The scholars, in addition to the issue of the origin of morality and its relations to the origin of man as a species, point out to the fact that what underlies morality is empathy. We can observe it in the behaviour of animals, for example when "elephants help a young rhino come out of the marsh, or dolphins try to help whales attacked by whale hunters with a harpoon" (Elżanowski, 2010, p. 38). ${ }^{15}$ Although the sightings of such 'interspecific' empathy are rare, these examples lend credence to them and justify our expectations that what underlies them is a spontaneous compassion for the suffering of other animals, just as for their own. ${ }^{16}$ Today we know that even animals

15 The phenomenon of altruism, observable in many species, is quoted as a manifestation of rudimentary moral behaviour. Perhaps one should differentiate between interspecific altruism and altruism that is akin to interspecific altruism, but the sheer fact of the occurrence of 'helping others' may provoke questions of the sources of morality in general. Studies on these issues have been carried out on many species and under many circumstances; cf. (Krebs, 2014, chapt. 11-13).

16 Elżanowski writes: "Empathy may have emerged as a necessity to adapt to the recognition of emotional states (...) among the members of one's own group, but also among the representatives of other species to situations and actions affecting their sensations (interests), therefore the recognition of their real experiences. Moral effects of empathy, i.e. a motivation to help ...”; (Elżanowski, 2010, p. 39). 
that are phylogenetically distant receive certain stimuli as unpleasant and avoid them. The thought that in spite of the differences in the structure of the nervous system we should not belittle the capability of sensing pain in other organisms is much older than the physiological research results that validate it. Even in the times of Descartes, when the conviction, formulated by this philosopher that animals are machines incapable of feeling pain was prevalent, it was still believed that they were susceptible to suffering just like humans. What is important in this context is that this ability of compassion was transferred to other species and then to the surrounding world of animate and inanimate nature. The effect of such a perception of nature might have been the vision of the Earth as a Mother that gives birth and suffers (Cf. Eliade, 2007, 2008).

Of course the attempts to introduce ethical norms from the process of evolution of life on the Earth arouse controversies. ${ }^{17}$ Regardless of whether we are in favour of formulating ethical content which is inspired by evolution and its non-biological consequences (behavioural, social), the question whether the visions of nature under scrutiny can also become a source of ethical norms still remains valid. In as much as in the context of Darwin's theory we may pose questions of the sources and the evolution of morality/ethics, in relation to contemporary conceptions we would rather ask about the degree to which their content regulates our attitude to nature. ${ }^{18}$ It seems justified even more, as these conceptions, like Darwin's theory, are results of a scientific, not religious consideration. Besides, we may also ask whether the possible ethical implications are accompanied by similar accusations to the ones formulated with regard to the theory of evolution, and whether they are refuted in a similar manner.

What binds these ideas is a fundamental vision of the changeability of matter that leads to the occurrence of conditions that enable the formation of organic life and, in consequence, a human being. In as much as in Darwin's theory the occurrence of life on the Earth did not imply the occurrence of higher organisms, and more, he thought that it was highly improbable as the mechanism of evolving species was characterised by coincidence ${ }^{19}$, other visions of nature seem to suggest in some interpretations that all the internal and external circumstances are 'scaled' in such a manner as to inevitably reach the goal of the intelligent life. Thus, these

17 Cf. (Elżanowski, 2010, p. 52).

18 Perhaps with an exception of this interpretation of the Hypothesis of Gaia where Gaia is treated, like in 'new-age' movements, as a personal and conscious being. Lovelock himself distances himself from such an understanding.

19 It is emphasised by all evolutionists, and it constitutes one of the arguments against this theory. This concerns, among others, the issue of 'time deficit'; cf. e.g. (F. Hoyle, 2003). 
conceptions have teleological features, though the theory of evolution was also viewed from that perspective. What can be the consequences of such features to our attitude to nature? Can the purposive vision of mechanisms that govern natural processes have an impact on our ethical relationship with nature, can it impact our morality? Does it make us feel that we are responsible for the surrounding environment?

The essence of the responsibility is not only the consciousness ${ }^{20}$ of the consequences of one's own actions and the knowledge of their results, the impact it has on us and our surroundings. Its indispensable element is also the possibility of free activity. How, in the context considered, are both elements (consciousness and freedom of activity) fulfilled? Neither the anthropic principle nor the Gaia Hypothesis negate or deny man the consciousness of action and freedom of choice (at least in the scope in which the functioning laws of nature allow it), yet our activity and our choices may be dictated by the vision of nature which we are building for ourselves. The model of the world functioning in accordance with invariable rules and heading inevitably towards a goal implies that the actions of conscious and free beings should be perceived in the appropriate perspective and scale - either cosmic or terrestrial. The anthropic principle and the Gaia Hypothesis suggest that nature functions and develops regardless of the actions of man. However, in as much as in the cosmological scale man is not capable (not at this time) of disturbing cosmic processes, ${ }^{21}$ in a global scale we can affect the life on Earth. But are we indeed capable of annihilating it and irreversibly destroying the mechanisms that regulate the processes responsible for the formation and sustenance of life? An affirmative answer to this question confers on us a responsibility for our actions, but weakens the significance of these visions of nature as a self-regulating mechanism that is independent of one of its creations. A negative answer on the other hand, despite enhancing the autonomy of anthropic mechanisms and Gaia, may induce to reject any actions that take into consideration the condition of the environment. ${ }^{22}$

20 It is not a cause for concern that conscience and freedom of choice are an inevitable element to talk about responsibility in any context. The lack thereof causes the problem of ethics against the environment and a possible guilt for unethical behaviour to fall.

21 But this may also change. When the accelerator near Geneva was first activated, the concerns about the initiation of the process leading to the creation of a black hole were taken seriously.

22 The formulation of the abovementioned situation as an alternative (or even as a disjunction) causes both standpoints to be irreducible. The knowledge which provides the framework for them is paradigmatically separate too. Besides, such a situation reminds the Greek 'Moira' - no matter what we do, nature, both on cosmological and earthly scales, will function in accordance with its own rules. 


\section{ETHICS TOWARDS THE ENVIRONMENT, I.E. CARING ABOUT ITS 'WELFARE'}

Speaking of an ethical attitude towards the natural environment, and, in more general terms, towards other beings and objects - people, cultural goods, etc. I mean such a behaviour which causes damage to no man or no thing and has a positive influence on them. ${ }^{23}$ However, contrary to what one may expect it is sometimes difficult to point to the content which would express the manner in which the notion of the 'good of the environment' is understood. For it is a term that values and relativizes, therefore its content should be dependent on a particular standpoint. A fundamental question arises of what we mean by the 'welfare of environment'. We may assume that it is its natural/original state. However, even here another issue arises - when does the environment preserve its natural/ original state? The most frequently heard answer to this question would be the statement that "we have in mind a state where human interference is not present" However, this answer contains two assumptions: first - it is assumed that human interference is always negative and, in a sense, unnatural. Secondly, that other species do not have impact on the environment, and at least not a negative one. Meanwhile, the state of environment is the effect of mutual interactions of many abiotic factors and, for over three billion years, also biotic ones. That taken into consideration, we next assume that these mutual relations are always positive for environment, which means they maintain its status quo. If this were not the case, no changes conditioned by evolution would take place, and therefore no new organisms or new interactions in the environment would occur. Lasting and unchangeable nature would be dead and 'would not create' any new beings. It would be a contradiction of the evolution mechanism, and both the anthropic principle and Gaia Hypothesis underline the fact that the world is changeable in all of its scales, yet under different factors.

The convictions above cause us to evaluate the impact of live organisms on our environment and a global scale in an insufficient manner. We usually treat it as positive or neutral. Underlying it is a conviction that for over three billion years living organisms have not contributed to the extinction of other organisms, that one species has not led to the extinction of another. In other words, we claim that extinction is not dependent on biotic factors and if it ever took place, it was

23 Using different words we might say that 'ethics' implies empathy. In other words being ethical means having empathy towards somebody/something. This brings to mind intentions in the sense of 'economy'. We have no doubts that the expression 'economy' relates to thriftiness (financial or formal, etc.). 
due to abiotic reasons (volcanic eruptions, earthquakes, cooling of the climate) or extraterrestrial factors (asteroids, cosmic radiation). Our belief in the unambiguously harmful activity of man is further reinforced when we are confronted with the fact that natural changes (or even cataclysms) led to the emergence of new species, and to biological diversity as a consequence.

Should we then pay heed to the transformations that we set in motion and their consequences if live organisms have been invariably shaping and changing the Earth for billions of years? Let us turn our attention to the most 'spectacular' impact that man has had on nature, which is the easiest to observe and the most severely felt, i.e. water and air pollution. However, according to Lovelock, they do not pose a serious threat to Gaia. ${ }^{24}$ What we may call pollution, that is the introduction of the so far marginal compounds to the functioning biosphere, is a constant phenomenon in nature. Many naturalists and philosophers who are concerned with nature give an example of atmosphere changes caused by the action of photosynthetic organisms which consisted in the production of oxygen and its emission to the atmosphere. ${ }^{25}$ Also state-of-the-art agriculture has a less negative impact on the environment than primitive agriculture which may appear to be a contradiction in terms from our pro-ecological point of view. We are convinced that extensive economy is more environmentally friendly. But burning off forests or an uncontrolled livestock grazing in areas which are naturally susceptible to erosions, contribute to the degradation of arable land in a higher degree than the intensive rural economy of Europe and America. Lovelock points out that this impact on nature depends on the type of environment. It is common knowledge that the most vulnerable areas in terms of human activity are located between the $45^{\text {th }}$ parallel of latitudes north and south of the Equator. Except for the air and water pollution and the effect of agriculture, the author lists a few other manifestations of human activity which may be potentially negative to the environment. They include: urbanisation, changes in carbon, nitrogen and sulphur circulation, greenhouse effect, ${ }^{26}$ ozone layer depletion, the application of DDT, demography (uncontrolled and unrestricted growth of

24 In this belief, the valuing nature of 'ethics' is revealed. We regard as harmful to the entire nature what is harmful to humans above all. We suggest a protection from something that has significance for man. He is the purpose and the value in itself. We are convinced that what is valuable to us is also of value to others.

25 This point was already made by Popper (Popper, 1997).

26 Lovelock had not envisaged the threat of rising temperature. According to him, the prognosis may sometimes be alarming, but the history of the Earth shows that nature is able to regulate its global temperature. One should note that the knowledge on the subject had not by then corroborated the most pessimistic of prognoses; cf. (Lovelock, 2003, p. 123). However, the last decade has made us realise that the darkest scenario may come to fruition. 
population). What is more, Lovelock goes on to claim that "none of human actions which lead to the pollution and deterioration of natural environment cannot be on a par with the natural devastation caused by continental glaciers". Every time the author lists the sources of potential threats for the biosphere, he emphasises their relative threat for the environment. This stems from the fact that Gaia has 'self-defensive' mechanisms capable of at least partial neutralisation of the threats. This relativity of man's negative impact on the environment consists also in (which is emphasised by Lovelock and may astonish the contemporary reader) the fact that human activity is not something exceptional to nature. If we treat pollution as a threat to the environment, it is only because our species contributes to that consciously. This is decisive for our perception of the impact that the man has on nature compared to other organisms.

We unwittingly assume that it is usually unfavourable as it alters the 'stable' nature that has been functioning for millennia in a manner that is harmful to most species. We also assume that these changes will not lead to the emergence of new ecological niches and at the same time they are not conducive to the emergence of new species. Human activity is unambiguously associated with the extinction of many species, and in the most extreme assumption, with the annihilation of the life on the Earth. However, in this case Lovelock also claims there is evidence to the contrary. According to him, the destruction of forest ecosystems was conducive to the emergence of grassy areas; the growing of hedgerows led to the formation of a 'mini' ecosystem in the rural landscape, as well as the formation of field baulks (Lovelock, 2003, p. 142 et al).

What underlies the beliefs that man is only capable of destroying nature is the fear that the changes introduced by him are not beneficial to him in the first place. If we speak about the need to act ethically in respect of the environment, it is on account of maintaining the conditions that enable the existence of our species, rather than for the sake of the well-being of other organisms, not to mention the nature 'itself' ${ }^{27}$ It appears that this conviction is not entirely unfounded. Man has evolved in a particular environment which was characterised by a particular topography, temperature, humidity and, therefore, vegetation, food resources, etc. Without delving into a distant, phylogenetic past, suffice it to say the drastically changing landscape and ecosystems in central Africa led to the emergence of Australopithecus and subsequently, the Homo species. Perhaps the contemporary

27 When analysing our drive to protect the environment, this anthropocentric aspect is very often called upon. Certainly, it may be comprised of multifarious strands, from economic and social to aesthetic and religious. However, extra-utilitarian strands, that are dictated by the well-being of nature, would be rare. Cf. e.g. (Bartkowski, 1979; Krebs, 2011). 
thinking in terms of stability and durability of nature (ecosystems) is grounded in the knowledge that our civilisation from the Neolithic until present day has been functioning in stable and relatively invariable climatic, botanical and even hydrological conditions. This means that we have existed in a relatively balanced and predictable biosphere for thousands of years. Local changes that have taken place in this time have not discontinued the species or the civilisation, at least not the one that was functioning in present day Near East and, subsequently, the Mediterranean Basin and Europe. ${ }^{28}$ The postulate of maintaining the unchanged environment is therefore rooted in the history of the Homo Sapiens that we are familiar with. This enhances the belief that any possible changes that may take place will be disastrous to us in the first place. One might hazard a guess that they are not dangerous or foreign to nature, but they are undesirable from our perspective.

However, despite these seemingly 'comforting' diagnoses regarding a potential influence of human activity on nature, Lovelock leaves no illusions. Biosphere is a network of interrelated organisms in which every species has strictly defined functions making an overall appearance of a global immunity system that regulates homeostasis of our planet (Lovelock, 2003, pp. 132-149). Unless man's activity disturbs or weakens this system, it is not a threat to Gaia, though he may bring danger upon himself. The problem lies in the recognition of those of its systems which are the most susceptible to change and which are essential to the survival of biosphere. Everything seems to indicate that currently we are witnessing changes in those most vulnerable spots in Gaia. They are not only dangerous to the existence of man but also to other species. This stability of biosphere also conditions the maintenance and functioning of our contemporary and highly technicalised civilisation which is, contrary to what might be expected, less immune to changes than primordial civilisations. Thus the protection of the stability of nature is at the same time a condition of the stability of modern civilisation. Given that it is global in character, it is prone to the effects of environmental imbalance, regardless of the place where it occurs on Earth. The consequences of this destabilisation

28 Perhaps the last cataclysm that seriously endangered the survival of the Homo Sapiens, was the eruption of the super volcano Toby in Sumatra around 74 thousand years ago. Only 1000 couples from our species in their reproductive years survived that eruption. Yet, even this event had some positive consequences: probably very dispersed groups were forced to exchange information much more frequently and precisely. This was conducive to the creation of more descriptive and abstract notions. The collapse of civilisations as described by Jean Dorst did not pose such a threat to our species. These civilisational catastrophes were, from the biological point of view, but local; cf. (Dorst, 1987). 
would have a global coverage and affect nearly all people. One may say that the more dependent we are on local conditions, the more vulnerable we become to the multitude of global threats. As a consequence, the unexpected 'blow' can be inflicted at any time anywhere, unless it is powerful enough. ${ }^{29}$

This interrelation of local and global changes is emphasised by Lovelock in the Gaia Hypothesis. He stresses the unique position of man in his conception, and at the same time his exceptional responsibility for environmental changes. The idea that all living organisms make changes to the environment which put them at risk of extinction, does not deprive man of the ability to predict the effects of his own actions. Because it is based on the analysis of data obtained by empirical sciences, the Gaia Hypothesis shows nature as a being linked by a network of interrelations which are only just being revealed by contemporary science. Although the conditions that occurred on the Earth are sometimes in apparent contradiction to such principles as entropy, they are not the outcome of forces that are contrary to universal laws, but they may only be a manifestation of their 'local disturbance', which are the consequence of conditions on the Earth and its nearest proximity. Understanding Gaia as a biosphere, and not as a human-like, caring Mother is conducive to the protection of nature for itself - nature understood as a network of interrelated elements which include man. This network indicates the fundamental interrelations in which the higher a given species is in the food chain, the more dependent it is of other organisms. On the other hand, such a species has less impact on the functions of nature. Put bluntly, we cannot survive without the environment, regardless of our technical achievements, whereas nature will go on without our species.

Although biosphere is capable of being reborn and creatively renewed, it is not indestructible. These are further consequences that stem from the Gaia Hypothesis. The history of Gaia presents it as a self-regulating 'super-organism' which still has certain tolerance limits the crossing of which can cause imbalance in the stability of biosphere and, in consequence the inability of its rebirth. In this context it is our ethical imperative towards nature to prevent, as far as possible, actions that cause these boundaries to be crossed. The warming climate is a fine example. Can we prevent this phenomenon and how should man behave in this situation? If the warming climate is a natural phenomenon, independent of man, then he is exempted from the liability for the course of this process. We are then not obliged to limit the emissions of exhaust fumes, deforestation, etc. The implementation of new

29 The destruction of oil fields has its ramifications (financial and social) in distant places in the world. 
technologies that are meant to protect environment and climate may be motivated economically or by the promotion of health at most. However, it is not driven by a concern for natural environment or a reaction to the effects of our actions. In this context the Gaia Hypothesis is not neutral. By propagating incessant changeability of biosphere and the fact that the climate warmed and cooled on several occasions, the Gaia Hypothesis may be conducive to the beliefs that cast doubt on the premises that make man responsible for the ongoing warming of the climate. ${ }^{30}$ There have been so many other living organisms that have and still do have impact on the atmosphere and the climate. But even here we can refer to our knowledge of limited regenerative abilities of biosphere. Charles Krebs is unambiguous about it: "the regulation of earthly atmosphere that is postulated in the Gaia Hypothesis might enable major changes in the composition of atmospheric gases within the limits of certain values which can never be crossed. From the perspective of man, even if the Gaia Hypothesis were to be correct, we may not forget about the causes of climate changes in a naive hope that Gaia will save us from the consequences of our crazy emissions of greenhouse gases” (Krebs, 2011, p. 368).

The knowledge of the increasingly detailed interrelations between organisms and between them and the abiotic environment also puts the responsibility for the choice of principles and methods of environmental protection on man. The old dilemma, whether to protect species or their biotopes seems to be anachronistic today. None of the species will survive without its environment, but we also know that their protection must have a global reach. The protection of hatcheries is not enough to save a bird species when its wintering grounds thousands of miles away will start disappearing. The same is true for migrating fish, mammals, insects, etc.

Let us reiterate. Although the Gaia Hypothesis confers on man a surprising amount of freedom and lifts the burden of threat from the most obvious of his actions, it points to dangers where they are expected the least. Gaia ${ }^{31}$ is capable of regenerating, but it also has other soft spots - the areas which should be the object of our concern. Returning to the example of destructive effects of continental

30 Doubts concerning man's impact on the climate are still raised.

31 Let us repeat once more that Gaia may only be understood as biosphere which is comprised of biomes, biocenoses, biotopes and ecosystems. All these 'ecological units' reflect, more or less accurately, a natural system in nature. Yet they always represent the interrelations within them which are subject to increasingly more complex system whose reach is increasingly more global. Ultimately, they function (or their functioning can be thus described) within biosphere. In this context one may truly get the impression that the way in which nature works may be ordered with a purpose, and this might be conducive to some interpretations assuming conscious and intelligent design. The teleological character of the history of the world was also emphasised by alchemists. 
glaciers and actions of man, Lovelock observes that "fertile tropical lands remained outside the destructive active activity of man in the past and they could balance the losses brought about by continental glaciers” (Lovelock, 2003, p. 138). However, will Gaia have a 'place to hide' now that our civilisation has extended globally and its effects are visible all around the globe?

\section{CONCLUSION}

Karl R. Popper in his article The Moral Responsibility of the Scientist writes: "if a naturalist has been irrevocably involved in the applications of science, he should also consider as his responsibility an anticipation, in a possible degree, of unintended effects of his work and pay particular attention to those which need to be avoided from the start” (Popper, 1997, p. 146).

As it was already mentioned, different content formulated by naturalists may be intertwined with practical applications. Even the highly abstract and holistic conceptions such as the anthropic principle or the Gaia Hypothesis which, as it may seem, should not directly translate to practical, or even more so, technical ${ }^{32}$ side of our daily lives, are decisive as far as our attitude towards the surroundings is concerned. There is a temptation to treat those ideas of the unity of nature and man as ethically neutral or even lifting our ethical responsibility for the environment. Conducive to this might be the belief that is encapsulated in the discussed conceptions of the inevitability of natural processes, of the irreversibility of phenomena that lead to a particular goal in a completely determined manner. We may imagine that within the framework of the anthropic principle and the Gaia Hypothesis, the reason why we are exempted from the responsibility for the environment is that, with a certain interpretation, we have the impression that whatever we do, the Cosmos, Gaia, Genes, Phenotypes and social mechanisms will function in accordance with their own particular objectives. Or, whatever we do, it will be on such a small scale in time and space, that our actions will not only have minimal impact on the Cosmos and the life on the Earth, but also our phylogenetic development. In other words, it may only be of significance in the individual, personal dimension. Therefore, nature thus presented in the conceptions above would be independent

32 In the mentioned article, Popper makes a strong link between the technical side and its military consequences. The development of contemporary weaponry, from firearms to nuclear bombs, would not be possible if it were not for a technical progress that encompasses many fields related to research of nature. Ballistics, chemistry, biology or nuclear physics are the indispensable 'components' of 'arms race'. 
of 'local' actions, and not even man would be able to disturb the fundamental course of the evolution of nature. In that case, would such teleological visions exempt man from the obligation to build ethical relations with the environment? I do not think so. For it is such visions of nature, by making our knowledge of it more profound, make us feel more responsible for it. Changes in the understanding of the mechanisms that function in nature and a growing awareness of the interrelations between all the elements of biosphere induce changes in the approach to its protection. Understanding nature as a whole, a system ${ }^{33}$, the 'chain of being', makes us realise the versatility of the principles that govern its protection the more we learn its complexity. The protection of a species or a biotope as a system that binds organisms and the environment, must take place in a global scale, the more so as we realise the scope of changes that we introduce.

The understanding of these relations, and also those which appear as a result of human activity, is expressed in the conceptual schema of the processes of the emergence of further states from biosphere which reflect our perception of nature. We move from biosphere to anthroposphere, only to proceed to technosphere. Today, in the age of telecommunicational revolution and microtechnology, we can speak about nanosphere. These new methods of articulating nature impose on us a different philosophy of environmental protection.

On the other hand, those visions of nature, built upon scientific discoveries, make us dependent on science and its methodology. Changes within them (one would almost say "changes in the paradigm") also transform our relationship towards nature. All this is additionally linked to the functioning culture which sets goals and research methods. This was emphasised not only by Popper but also Jean Dorst. In his book The Force of Life he wrote: "Ideas govern the world and dictate everyone their behaviour (...) The first remark that imposes itself is that none of the beliefs that shape our doctrines and ways of comprehending could engrain in us the respect for our natural capital or teach us to protect it” (Dorst, 1987, p. 78). ${ }^{34}$ It is not the most optimistic vision of our potential motives for protecting nature. One may be tempted to put forward a thesis that nowadays only

33 It must be added here that the ontology of nature is changed because of that. This was observed at the beginning of the twentieth century by Whitehead, who proposed a change of its ontological status that manifests itself in its processisation. Nature ceased to be an arena of quantified matter and events and 'started' functioning as a stream of a countless number of relations and interconnections. Cf. (Whitehead, 1987).

34 More on this in my article Man and nature - is the seed of destruction always embedded in the idea of progress? W dziewięćdziesiq̨ta rocznicę urodzin Jeana Dorsta, [At the Ninetieth Anniversary of Jean Dorst’s Birthday] “Kultura i wartości” [Culture and Values] 1(13)/2015, Lublin. 
scientific knowledge is the source of concern for nature and that it must generate the motives, methods and purposes for their protection.

Yet the proposed goals of natural protection are not free from doubt either. What would be the purpose of environmental protection? Would it be for the sake of nature itself, regardless of the consequences that lie outside nature? Or are there always some other hidden purposes, e.g. economic, social, political, etc.? Ecology always instils emotions, especially on account of its far-flung consequences for the economy, which on the other hand is closely linked to politics (sadly, with shortsighted politics). What is more, if we clearly assume that our ethical relationship towards nature is also conducive to the well-being of man, we also need to answer the question of what kind of well-being we mean - is it a spiritual or material well-being?; is it available to the largest number of people possible or only to the chosen ones? Let us again ask if we can implement the idea of man's well-being in isolation from the well-being of nature?

And to conclude - if we notice a return of 'sacralisation' of nature ('New Age' and other movements) then aren't they secondary in nature, i.e. aren't they an effect of a better and more profound understanding of the complexity of biosphere? And above all a new look at the human dependence upon this universe and the growing awareness of our integrity with nature. The only difference is that this 'sacralisation' is not supported by transcendent beings and ideas but new view on matter. We may say that it is science that contributes to the renewed (rationalised?) sacralisation of nature.

\section{References:}

Bartkowski, T. (1979). Kształtowanie i ochrona środowiska [Shaping and protecting the environment]. Warszawa: PWN.

Dorst, J. (1987). Siła życia, [The Force of Life].Ttransl. W. Dłuski. Warszawa: PIW.

Eliade, M. (2007). Kowale i alchemicy, [Blacksmiths and Alchemists]. Transl. A. Leder. Warszawa: Aletheia.

Eliade, M. (2008). Sacrum a profanum. Transl. B. Baran. Warszawa: Aletheia.

Elżanowski, A. (2010). Prawdziwie darwinowska etyka [Truly Darwinian Ethics], [in:] Ewolucja, filozofia, religia [Evolution, philosophy, religion], „LECTIONES \& ACROASES PHILOSOPICAE” III. Wrocław: Polskie Forum Filozoficzne.

Hoyle, F. (2003). Matematyka ewolucji [Mathematics of Evolution]. Transl. R. Piotrowski, Warszawa: Megas.

Jay-Gould, S. (1991). Niewczesny pogrzeb Darwina [Darwin’s Untimely Burial]. Various transl. Warszawa: PIW.

Kołakowski, L. (1994). Obecność mitu [The Presence of the Myth], Wrocław: Wydawnictwo Dolnośląskie. 
Koyre, A. (1995). Mistycy, spirytualiści, alchemicy niemieccy XVI wieku, [German Mystics, Spiritualists and Alchemists of the $16^{\text {th }}$ Century]. Transl. L. Brogowski. Gdańsk: Słowo/ Obraz.

Krebs, C.J. (2011). Ekologia, [Ecology]. Various transl. Warszawa: PWN.

Krebs, J.R. Davis, N.B. (2014). Wprowadzenie do ekologii behawioralnej [An Introduction to Behavioural Ecology]. transl. M. Golachowski. Warszawa: PWN.

Lovelock, J. (2003). Gaja. Nowe spojrzenie na życie na Ziemi [Gaia. A New Look at Life on Earth]. Transl. M. Ryszkiewicz. Warszawa: Prószyński i S-ka.

Piątek, Z. (2008). Ekofilozofia [Ecophilosophy]. Kraków: Wyd. UJ.

Popper, K.R. (1997). Mit schematu pojęciowego [The Myth of the Framework]. Transl. B. Chwedeńczuk. Warszawa: Książka i Wiedza.

Tyburski, W. (2013). Dyscypliny humanistyczne i ekologia [The Humanities and Ecology]. Toruń: WN UMK.

Ward, P. (2010). Hipoteza Medei. Czy życie na Ziemi zmierza do samounicestwienia? [The Medea Hypothesis. Is Life on Earth Ultimately Self-Destructive?]. Transl. M. Betley, Warszawa: Prószyński i S-ka.

Whitehead, A.N. (1987). Nauka i świat nowożytny, [Science and the Modern World]. Transl. M. Pieńkowski OP. Kraków: ZNAK. 